\title{
Comparison of Commercial and Locally Identified Yeast Strains in Relation to Young Wine Quality of Cabernet Sauvignon
}

\author{
A.K. Sharma*, S.D. Sawant, P.G. Adsule and Y.R. Rajguru \\ National Research Centre for Grapes, Pune (India) - 412307 \\ Submitted for publication: August 2009 \\ Accepted for publication: October 2009 \\ Key words: Cabernet Sauvignon, yeast strains, young wine, antioxidant properties
}

\begin{abstract}
The present study was conducted to evaluate the fermentation efficiency of locally identified yeast strains against the commercial yeast preparations in the case of Cabernet Sauvignon wines. For this purpose, must of Cabernet Sauvignon was inoculated separately with three each of commercial (KIV 1116, EC 1118 and Premier Cuvee) and locally identified (RS1, RS2 and RS3) yeast strains. The physicochemical parameters of wines made with these two groups of yeast strains showed significant differences during fermentation. The pH values ranged from 3.40 to 3.55, which fall in the agreeable limit. The minimum alcohol content, i.e. $10.32 \%$, was found in the wine with maximum reducing sugars. Wine made from the inoculation of strain EC 1118 contained $11.06 \%$ alcohol. The anthocyanin content differed significantly among all the yeast strains. The maximum anthocyanin content was found in wine prepared from RS1 (15.70 g/l). Maximum colour intensity (14.66) was observed in the RS2 yeast strain. The wines made from locally identified yeast strains contained more antioxidant reducing power (FRAP) than commercially available yeast strains. Significant differences were noted among the yeast strains in relation to FRAP values. The locally identified yeast strains were found to be on par with commercial yeast strains. These strains can be used for further studies on other important varieties.
\end{abstract}

Winemaking involves a diverse set of factors that play an important role in the conversion of grapes to wine. The most important factors during winemaking are vineyard management practices, grape composition at maturity, winemaking practices and commercial yeast selection. The microorganisms responsible for ethanol production were identified as yeasts during the second half of the 19th century by Demain and Solomon (1981). Countless studies have since then confirmed that yeasts play a critical role in determining the body, colour, flavour and aroma of wine. The final product of grape must fermentation is the result of a combined action of different yeast species, which contribute in different ways to the sensory properties of wine (Romano, 1997).

Traditional wine fermentation is a complex heterogeneous microbiological process involving a sequential development of various yeasts and other microorganisms present in musts, such as moulds and lactic and acetic acid bacteria. However, it is accepted that strains of Saccharomyces cerevisiae, known as "wine yeast", are especially well adapted to this process and play a major role in the fermentation of grape musts (Rankine, 1968; Martini and Vaughan-Martini, 1990; De Barros Lopes et al., 1998). The importance of each yeast source in the vineyard and winery may vary greatly, depending on a large variety of factors, such as climatic conditions, including temperature and rainfall in the region/site, the geographic location of the vineyard, the harvest technique, grape variety, the age of the vineyard and the soil type (Pretorius, 2000).

Today, the majority of wine production is based on the use of commercial strains - yeast preparations that have been isolated from vineyards or wineries and selected for their superior properties for winemaking. Virtually all commercial yeast strains used for winemaking in India are imported by the commercial wineries. However, locally selected yeast strains have their own importance in winemaking and affect the wine quality. Considering the above facts, the present study was undertaken to evaluate the bioefficacy of locally identified wine yeast during the initial fermentation of Cabernet Sauvignon wines.

\section{MATERIALS AND METHODS}

The present study was carried out during the grape cropping season of 2009 at the National Research Centre for Grapes in Pune. The bunches of Cabernet Sauvignon were harvested when the total soluble solids (TSS) content was more than $20^{\circ} \mathrm{B}$. The berries were destemmed manually and crushed or juiced. To suppress the development of natural micro-flora, $100 \mathrm{ppm}$ potassium metabisulphate (KMS) was added to the must/juice and stored at $0^{\circ} \mathrm{C}$ overnight. For this purpose, the must of Cabernet Sauvignon was inoculated with three commercial (KIV 1116, EC 1118 and Premier Cuvee) and three locally identified (RS1, RS2 and RS3) yeast strains. The fermentation was done in food grade plastic vessels placed at $24 \pm 2{ }^{\circ} \mathrm{C}$. The skin and seed separation was done on the tenth day after inoculation, and the wines were shifted at $0^{\circ} \mathrm{C}$ for a duration of two weeks. The wine samples were then collected for analysis.

\section{Preparation of active inoculums of yeast strains}

A volume of $200 \mathrm{~mL}$ of juice was placed in a $500 \mathrm{~mL}$ conical flask. The flask with juice was autoclaved at 15 psi for $20 \mathrm{~min}$. These sterilised flasks were allowed to cool at room temperature. Pure yeast culture at a cell count of $8.9 \times 10^{5} / \mathrm{mL}$ was inoculated into the flask aseptically. The flasks were incubated for at room temperature 48 to $72 \mathrm{~h}$. 


\section{Physicochemical analysis}

The wines were analysed for $\mathrm{pH}$, volatile acidity and reducing sugars. The $\mathrm{pH}$ values of the samples were noted with the help of the wine analysing system of Metrohm. The reducing sugar was estimated by the DNSA method, and glucose stock solution (Merck) was used as a standard. Absorbance was taken at $540 \mathrm{~nm}$ using the Pharma Spac 1700 UV spectrophotometer (SHIMADZU: UV-Visible Spectrophotometer). The alcohol content in the wines was determined by SHIMADZU 2010 gas chromatography (GC), by using standards. Standard operating procedures were followed for sample preparation. The injector port temperature of the GC was $200^{\circ} \mathrm{C}$, and the injector volume of the solution was $1 \mu \mathrm{l}$. The Flame Ionisation Detector (FID) was used at a temperature of $250^{\circ} \mathrm{C}$. A CP-WAX-57 CB (50 m X $0.25 \mathrm{~mm}$ ID) column was used. Calibration curves were obtained by plotting the peak areas against different concentrations of alcohol.

The titration method was used for the determination of total $\mathrm{SO}_{2}$ and free $\mathrm{SO}_{2}$ (Zoecklein et al., 1994). The wine samples were diluted 1:10 and colour intensity was measured at $420 \mathrm{~nm}, 520 \mathrm{~nm}$ and $620 \mathrm{~nm}$. Total phenols in the wines were estimated as per the method suggested by Singleton and Rossi (1965). Absorbances were taken at $765 \mathrm{~nm}$ with a UV spectrophotometer. A method suggested by Fuleki and Francis (1968) was followed to estimate the anthocyanin concentration in the wines.

Ferric ion-reducing antioxidant power (FRAP) was estimated following the method of Benzie and Strain (1996). Quercetin standards of different concentrations were taken directly with the UV spectrophotometer immediately after the addition of 0.9 $\mathrm{mL}$ of FRAP solution. A standard curve was prepared for the quercetin solutions and the amount of antioxidant in the samples was estimated from the curve. For the estimation of free radical scavenging activity by the DPPH assay, the method suggested by Arnous et al. (2001) was adopted. The readings were taken with a UV spectrophotometer at $515 \mathrm{~nm}$. A standard curve was prepared using Trolox solutions and the amount of free radical in the samples was estimated from the curve.

\section{RESULTS}

The data presented in Table 1 show significant differences among yeast strains in the studied parameters of Cabernet Sauvignon wines. The $\mathrm{pH}$ values ranged from 3.40 to 3.55 , which fall in the agreeable limit. The maximum $\mathrm{pH}$ (3.55) was recorded in wine prepared from KIV 1116, and the minimum $\mathrm{pH}$ (3.40) was in wine produced from the RS3 strain. The values for volatile acidity ranged from 0.010 to $0.016 \mathrm{~g} / \mathrm{L}$ and differed non-significantly. The wine from strain RS1 contained the minimum volatile acidity, i.e. $0.010 \mathrm{~g} / \mathrm{L}$, and the maximum $(0.016 \mathrm{~g} / \mathrm{L})$ was noted in wine made from KIV 1116. The wine from KIV 1116 had the minimum reducing sugar (8.14 $\mathrm{g} / \mathrm{L})$, and the wine produced from RS3 had the maximum (12.54 $\mathrm{g} / \mathrm{L})$ reducing sugar content. This is also reflected in the alcohol content of the wines. The minimum alcohol content, i.e. $10.32 \%$, was in the wine with the maximum reducing sugars. However, an $11.06 \%$ alcohol content was noted in wines produced from the EC 1118 strain, which recorded a $9.67 \mathrm{~g} / \mathrm{L}$ reducing sugar content. Minimum free $\mathrm{SO}_{2}$, i.e. $160 \mathrm{mg} / \mathrm{L}$, was recorded in wine from RS3, followed by the wines produced from RS1, EC 1116 and Premier Cuvee, with a total of $176 \mathrm{mg} / \mathrm{L}$. Higher free $\mathrm{SO}_{2}$ was noted from the RS2 strain (200.00 mg/L). The wines made from RS1, EC 1118 and Premier Cuvee were registered with a maximum quantity of total $\mathrm{SO}_{2}$, i.e. $304 \mathrm{mg} / \mathrm{L}$, while the minimum total $\mathrm{SO}_{2}(240 \mathrm{mg} / \mathrm{L})$ was noted in the case of the KIV 1116 strain.

The anthocyanin content differed significantly among all the yeast strains. The maximum anthocyanin content was found in wine prepared from RS1 (15.70 g/L), followed by Premier Cuvee, and the lowest $(10.17 \mathrm{~g} / \mathrm{L})$ was recorded in wine made with the inoculation of KIV 1116 (Table 2). A locally identified yeast strain, viz. RS3, extracted the maximum total phenols $(4.91 \mathrm{~g} / \mathrm{L})$ in the wine, followed by RS1. The wine made from inoculation with a commercial yeast strain, viz. Premier Cuvee, had the minimum total phenol content, with a value of $4.41 \mathrm{~g} / \mathrm{L}$. The colour intensity of the wines was also affected significantly by yeast strain. Maximum colour intensity (14.66) was observed with the RS2 yeast strain. However, wines made from the RS2 yeast strain contained less anthocyanin and total phenols than the others. The minimum colour intensity was noted in wines made from KIV 1116. Significant differences were noted among the yeast strains in relation to FRAP values. The wines made from the inoculation of RS1 yeast strain registered a maximum FRAP value, i.e. $0.250 \mathrm{mg} / \mathrm{L}$, followed by that from RS3. KIV 1116 had the minimum FRAP value. It is clear from the data that wines made from locally identified yeast strains contained more antioxidant reducing power (FRAP) than commercially available yeast strains. In the case of free radical scavenging activity, which was measured by the DPPH assay, wines made from inoculation with commercially available yeast strains were superior to wines made with inoculation with locally identified yeast strains.

\section{TABLE 1}

Effect of yeast strains on physicochemical parameters of Cabernet Sauvignon wines.

\begin{tabular}{|c|c|c|c|c|c|c|}
\hline \multirow[b]{2}{*}{ Yeast strains } & \multicolumn{6}{|c|}{ Parameters } \\
\hline & pH & $\begin{array}{c}\text { Volatile acidity } \\
\text { (g/L) }\end{array}$ & $\begin{array}{c}\text { Reducing sugars } \\
(\mathrm{g} / \mathrm{L})\end{array}$ & Alcohol \% & $\begin{array}{c}\text { Free } \mathrm{SO}_{2} \\
(\mathrm{mg} / \mathrm{L})\end{array}$ & $\begin{array}{c}\text { Total SO}_{2} \\
(\mathrm{mg} / \mathrm{L})\end{array}$ \\
\hline RS1 & 3.48 & 0.010 & 11.48 & 10.72 & 176.0 & 304.0 \\
\hline RS2 & 3.52 & 0.014 & 10.03 & 10.42 & 200.0 & 288.0 \\
\hline $\mathrm{RS} 3$ & 3.40 & 0.014 & 12.54 & 10.32 & 160.0 & 272.0 \\
\hline KIV 1116 & 3.55 & 0.016 & 8.14 & 10.37 & 184.0 & 240.0 \\
\hline EC 1118 & 3.48 & 0.011 & 9.67 & 11.06 & 176.0 & 304.0 \\
\hline Premier Cuvee & 3.53 & 0.013 & 10.45 & 10.62 & 176.0 & 304.0 \\
\hline $\mathrm{SEM} \pm$ & 0.012 & 0.001 & 0.211 & 0.033 & 3.545 & 2.503 \\
\hline LSD at $5 \%$ & 0.04 & NS & 0.65 & 0.10 & 10.68 & 7.54 \\
\hline
\end{tabular}


TABLE 2

Chromic and antioxidant properties of Cabernet Sauvignon wines as affected by yeast strains.

\begin{tabular}{cccccc}
\hline \multirow{2}{*}{ Yeast strains } & \multicolumn{5}{c}{ Parameters } \\
\cline { 2 - 6 } & Anthocyanin (g/L) & Phenolics (g/L) & Colour intensity & FRAP (mg/L) & DPPH (mM) \\
\hline RS1 & 15.70 & 4.41 & 11.52 & 0.250 & 0.053 \\
RS2 & 12.10 & 3.63 & 14.66 & 0.180 & 0.047 \\
RS3 & 13.41 & 4.91 & 13.22 & 0.200 & 0.048 \\
KIV 1116 & 10.17 & 3.67 & 12.68 & 0.130 & 0.060 \\
EC 1118 & 12.35 & 4.02 & 14.00 & 0.160 & 0.072 \\
Premier Cuvee & 15.11 & 3.93 & 13.87 & 0.180 & 0.100 \\
SEM \pm & 0.034 & 0.028 & 0.022 & 0.016 & 0.020 \\
LSD at 5\% & 0.11 & 0.08 & 0.075 & 0.05 & NS \\
\hline
\end{tabular}

\section{DISCUSSION}

The acidity of grape juice and wine plays an important role in many aspects of winemaking and wine quality, including the sensory quality of the wine and its physical, biochemical and microbial stability (Caputi \& Ryan, 1996). The physicochemical parameters of wines made with different yeast cultures show significant differences, except in relation to volatile acidity. These results were similar to those of Vilanova and Massneuf-Pomarede (2005). These authors also observed significant differences when analysing the physicochemical parameters of wines made from different yeast strains. These wines were highly acceptable. The commercial yeast strain, i.e. EC 1118, utilised the reducing sugar more efficiently than other strains. The wine made from EC 1118 had the maximum alcohol content, i.e. $11.06 \%$, followed by that made from RS1 and Premier Cuvee, with values of 10.72 and $10.62 \%$ respectively. The RS1 has good potential for the efficient utilisation of sugars for the production of alcohol over and above the other, locally identified yeast strains. The specific environmental conditions in the must, viz. high osmotic pressure, the presence of $\mathrm{SO}_{2}$, temperature and cellar hygiene, all play a role in determining which species can survive and grow in the must (Longo et al., 1991). The effect of yeast strains was recorded in the total and free $\mathrm{SO}_{2}$ content in wines. Yeast strains differ widely in their ability to produce sulphite and sulphide (Henschke \& Jiranek 1993). However, in addition to strain effect, the nutrient composition of the grape juice, the concentration of sulphate, must clarification, the initial $\mathrm{pH}$ and temperature all affect sulphite formation by wine yeasts (Rauhut, 1993).

Wines made from different yeast strains differed in their antioxidant activities, including chromatic properties. These results confirmed the results of Caridi et al. (2004). The strain behaviour was found to somewhat modify the chromatic properties, phenolic profile and antioxidant power of wine when these authors studied twenty-two parameters in red wines. Very significant differences were observed for colour intensity, total polyphenols and non-anthocyanic flavonoids.

\section{CONCLUSION}

On the basis of the results from preliminary studies conducted to evaluate the locally identified yeast strains in comparison to commercially available yeast cultures, it may be concluded that the locally identified yeast strains were found to be equally good in terms of the quality parameters of Cabernet Sauvignon wines. In some cases, these strains were found to be better than commercially available yeast preparations. However, further studies on other commercially important red as well as white wine varieties are needed to confirm the results and to confirm the exploitation of locally identified strains on the commercial level.

\section{LITERATURE CITED}

Arnous, A., Makris, D.P. \& Kefalas, P., 2001. Effect of principle polyphenolic components in relation to antioxidant characteristics of aged red wines. J. Agric. Food Chem. 49, 5736-5742.

Benzie, I.F.F. \& Strain, J.J., 1996. The ferric reducing ability of plasma (FRAP) as a measure of "antioxidant power": the FRAP assay. Anal. Biochem. 239, 70-76.

Caputi, A. Jr. \& Ryan, T., 1996. Must and wine acidification. Presentation at a meeting of the OIV Expert Group Technologie du Vin, Paris.

Caridi, A., Cufaril, A., Lovino, R., Palumbo, R. \& Tedesco, I., 2004. Influence of yeast on polyphenol composition of wine. Food Technol. Biotechnol. 42, 37-40.

De Barros Lopes, M., Soden, A., Martens, A.L., Henschke, P.A. \& Langridge, P., 1998. Differentiation and species identification of yeasts using PCR. Int. J. Syst. Bacteriol. 48, 279-286.

Demain A.L. \& Solomon N.A., 1981. Industrial microbiology: introducing an issue of how products useful to man are manufactured by microorganisms. Sci. Am. 245, 43-51.

Fuleki, T. \& Francis, J., 1968. Quantitative methods for anthocyanins. 1. Extraction and determination of total anthocyanin in cranberries. J. Food Sci. 33, 72-78.

Henschke, P.A. \& Jiranek, V., 1993. Yeasts - metabolism of nitrogen compounds. In G.H. Fleet (ed.). Wine microbiology and biotechnology. Harwood Academic, Reading. pp. $77-164$

Longo, E., Cansado, J., Agrelo, D. \& Villa, T.G., 1991. Effect of climatic conditions on yeast diversity in grape musts from Northwest Spain. Am. J. Enol. Vitic. 42, 141-144.

Martini, A. \& Vaughan-Martini, A., 1990. Grape must fermentation: past and present. In J.F.T. Spencer \& D.M. Spencer (eds.). Yeast technology. SpringerVerlag, pp 105-123.

Pretorius, I.S., 2000. Tailoring wine yeast for the new millennium: novel approaches to the ancient art of winemaking. Yeast 16, 675-729.

Rankine, B.C., 1968. Formation of alpha-ketoglutaric acid by wine yeasts and its oenological significance. J. Food Sci. Agric. 19, 624-629.

Rauhut, D. 1993. Yeast - production of sulfur compounds. In G.H. Fleet (ed.). Wine microbiology and biotechnology. Harwood Academic, Reading. pp. 183 - 223.

Romano P., 1997. Metabolic characteristic of wine strains during spontaneous and inoculated fermentation. Food Technol. Biotechnol. 35, 255-260.

Singleton, V.L. \& Rossi, J.A., 1965. Colorimetric of total phenolics with phosphomolibdic-phosphotungstic acid reagent. Am. J. Enol. Vitic. 16, 144-158.

Vilanova, M. \& Massneuf-Pomarede, I., 2005. Characterization of yeast strains from Rias Baxas (NW Spain) and their contribution to fermentation of Albarino wine. Annals Microbiol. 55, 23-26.

Zoecklein, B.W., Fugelsang, K.C., Gump, B.H. \& Nury, F.S., 1995. Wine analysis and production. Chapman and Hall, New York. pp. $338-496$. 